\title{
MELANOMAS MALIGNOS DO REBORDO ALVEOLAR NA MAXILA: APRESENTACGAO DE UM CASO
}

\author{
Prof. Luiz Kosminsky * \\ Prof. Fernando Amaral ** \\ Prof. Ageu de Aquino Sales *** \\ Prof. Wellingtom Macedo ****
}

\section{S I N 0 P $\mathbf{S} \mathbf{E}$}

Melanoma maligno, localizado primariamente no rebordo alveolar do maxilar superior, apresenta-se numa mulher branca de 36 anos de idade. A peça protética desempenhou provável ação irritativa, precipitando o aparecimento de prévia modificação de cor. 0 tratamento radioterápico foi ineficaz. A morte por metástases gerais ocorreu em menos de um ano, após tratamento. Pequena média de sobre vida. Tumor cujo tratamento deve ser essencialmente cirúrgico, pouco radiosensível.

A revisão da literatura mostra que melanomas primários localizados na cavidade bucal, são tumores raros, porém CHAUDHRY e col. (4) afirmam que os referidos tumores não são tão incomuns como o número de casos relatados indicam. 0 mesmo autor, revendo bibliografia de 1857 à 1957 , consequentimente, um século de pesquisa na literatura, constatou apenas 105 casos de melanomas malígnos, primários, na cavidade bucal, sendo que $85 \%$ se desenvolviam no maxilar superior, destes, $51 \%$ localizavam-se no palato duro, $26 \%$ no rebordo alveolar e $8 \%$ no palato mole.

Dos casos notados, $73 \%$ ocorreram em brancos, $27 \%$ em pessoas de outras raças; duas vezes mais frequentes no homem do que na mulheer, e $90 \%$ verificados em pessoas acima de 30 anos de idade. Assim, nota-se que são tumores da idade adulta, sendo o caso mais idoso constatado num paciente de 83 anos de idade, fato relatado por CHARKOUDIAN (3), segundo trabalho apresentado por SELDIN (9) e colaboradores.

Segundo o critério adotado por GREENE e col (7), para se afirmar que o melanoma malígno é primário na cavidade bucal, tem que ser demonstrado sua presença na mucosa bucal, apresentar atividade juncional

* Regente da Disciplina de Patologia Buco-dental da Faculdade de Odontologia, UFRPe

* Prof. Assistente da I * Disciplina de Clínica Odontológica da Faculdade de Odontologia da UFPe.

*** Regente da Disciplina de Radiologia da Faculdade de Odontologia da UFPe.

**** Prof. Assistente do Departamento de Histoquímica do Instituto de Biociências, UFPe. 
e a imposibildade de ser constatada em qualquer outro lugar do corpo.

Baseado neste conceito, podemos afirmar que o caso presente se enquadra perfeitamente dentro do referido critério.

\section{APRESENTAÇÃOO DO CASO:}

Em fevereiro de 1968, uma mulher branca, de 36 anos de idade, casada, de prendas domésticas, residente no interior do estado, na época hospitalizada em tratamento ginecológico, nos procurou à conselho médico para diagnóstico de um tumor na cavidade bucal. Relatou que há aproximadamente oito meses passados, logo após a colocação da peça protética superior, o rebordo alveolar no maxilar ficou inflamado e sensível. Procurou pelo médico, que na ocasião alegou tratar-se de uma reação alérgica à peça. (sic).

Como antecedentes pessoais tinha tido dois abortos e fora portadora de mancha no pulmão direito, há mais de cinco anos passados, porém na ocasião estava curada. A mãe tinha falecido devido a tuberculose pulmonar.

No exame cérvico-facial, os ganglios linfáticos das cadeias sub-mentonianas e sub-mandibular direita, apresentavam-se enfartados, palpáveis e doloridos à palpação digital. No exame intra bucal, o maxilar superior era totalmente desdentado, apresentava na região vestibular, compreendida entre o canino esquerdo e o primeiro prémolar direito, manchas negras de formas irregulares, bem delimitadas; à altura dos incisivos cen- trais, abaixo do freio labial, sobressaía-se uma formação tumoral circunscrita, isto é, verdadeira pérola negra com tonalidade brilhante, de aproximadamente $0,5 \mathrm{~cm}$ de diâmetro, não ulcerado e não sangrando ao toque (fig. I)

$01^{\circ}$ prémolar superior direito que servia de apoio à peça protética tinha sido extraído. Nota-se que a dentadura era parcial, desprovida de grampos retentivos, apoios oclusais e gengiva artifical na região vestibular anterior, de estrutura e dentes confecionados em resina acrílica, com apoio palatino e no rebordo alveolar. (fig. II)

Colocada a prótese ressaltava-se o fato de que na região sem gengiva artificial, desenvolvia-se a doença (fig. III).

O diagnóstico clínico tentativo foi de possível melanoma malígno, dado as características apresentadas. Realizada a biópsia por excisão da pérola negra, com margem de segurança de $5 \mathrm{cms}$, ficou comprovado tratar-se de melanoma malígno, pelo aspecto histológico seguinte, conforme a fig. IV, isto é, células volumosas, redondas ou poliédricas, núcleo relativamente grande notando-se a intensidade da pigmentação melanina e presença de múltiplas figuras mitóticas.

Devido o prognóstico sombrio a família da paciente foi cientificada da gravidade do caso, bem como do plano de tratamento cirúrgico a ser executado no hospital do câncer, isto é, seria realizado a maxilectomia com esvaziamento ganglionar regional. Não houve autorização da famí- 


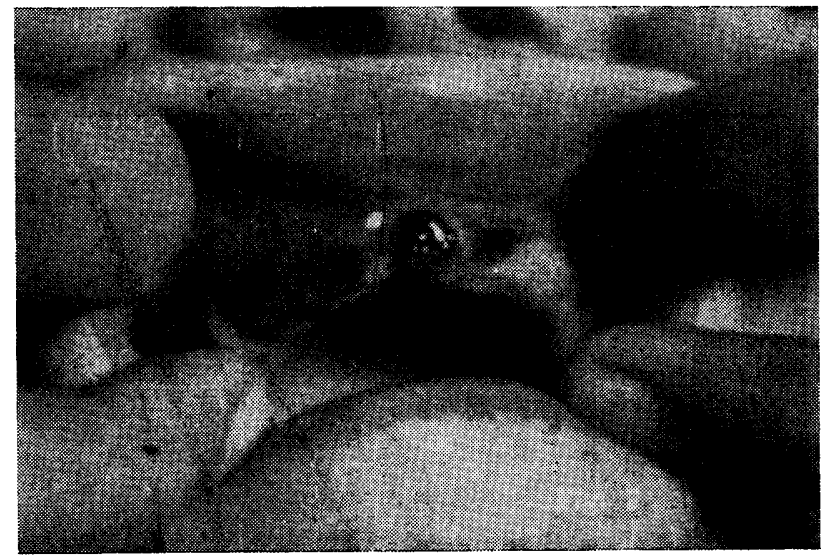

Fig. 1

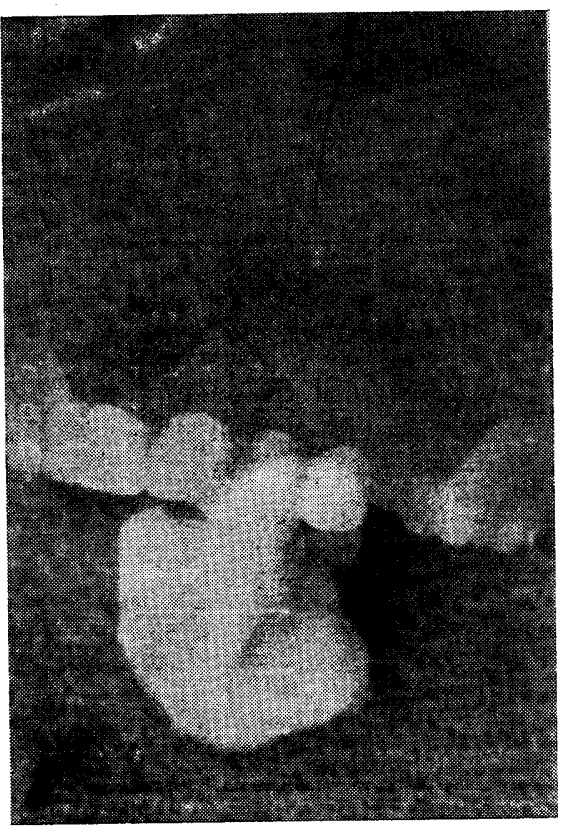

Fig. 2

R. Fac. Odont. P. A. 


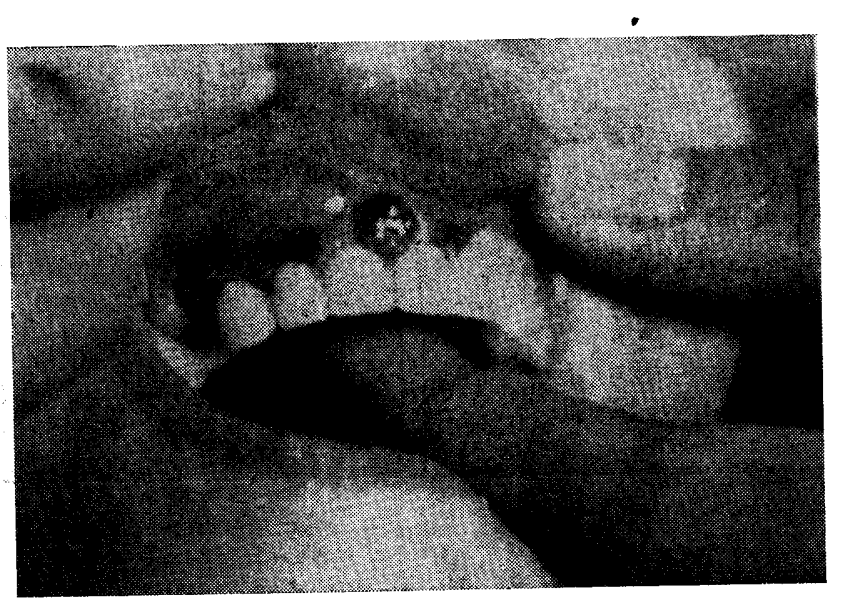

Fig, 3

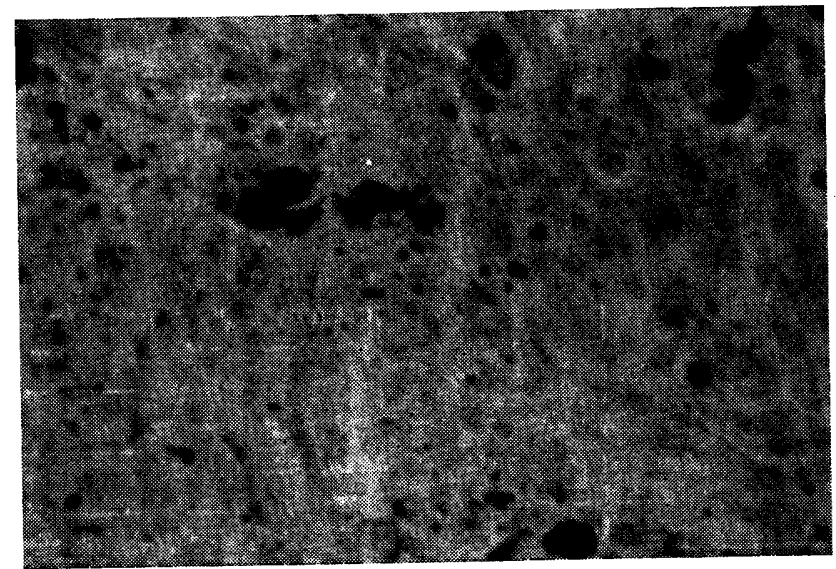

Fig. 4

R. Fac. Odont. P. A. 
lia consequentemente foi sugerido e aprovado o tratamento radioterápico, paliativo, o qual foi executado em trinta dias, constatando-se o desaparecimento das manchas negras do rebordo alveolar.

A paciente teve alta melhorada; meses mais tarde voltou ao hospital apresentando na cadeia lateral do pescoço, um nódulo volumoso, endurecido, dolorido, fixo e de coloração parda azulada, evidenciando a metástase.

Meses após, a paciente falecia devido a prováveis metástases, não tendo sido a sobrevida maior do que um ano após o diagnóstico e tratamento.

\section{DIsCUSSÃ}

A presença de melanoblastos na mucosa bucal tem sido demonstrada por diversos autores (2), estas células têm a capacidade de dar a melanoplacas, rarissimos nevus e melanomas malígnos através de processos ainda desconhecidos. Melanomas são tumores carcterizados pela propriedade latente ou manifesta que têm suas células de produzirem melanina (melanocitoma), pigmento que lhes confere coloração dešrita como castanha escuro, azulada ou negra. (8)

Sob o ponto de vista histogenético são tumores formados obrigatoriamen. te por melanoblastos, tendo na melanina uma das suas características principais, no entanto, esta pode estar ausente em áreas ou mesmo em todo o neoplasma, como ocorre nos apigmentados ou acrômicos.

Lógico é que o diagnóstico defini- tivo da lesão é dado pelo exame histopatológico, uma vez que é difícil a diferenciação das lesões pigmentadas, isto segundo Epstein (5).

AMATO (1) afirma que mesmo entre profissionais mais experimentados, a margem de erro no diagnóstico clínico atinge a $30 \%$. Discute-se se a biópsia deve ser incisional ou através da peça operatória. Baseados em dados fornecidos pelo California Tumor Registry, EPSTEIN (6) constatou 193 casos de melanomas malígnos em "que 115 foram feitas biópsias pré-operatórias apresentaram uma média de sobrevida superior aos 78 casos restantes, diagnósticados por excisão, isto é, cirurgia radical. Esta particularidade vem colocar dúvidas no antigo conceito de que a remoção parcial de um melanoma (por excisão) diminuiria ou afetaria a média de sobrevida. O importante, acreditamos, é não haver demora no diagnóstico do processo, bem como submeter o paciente a um tratamento imediato.

O prognóstico dos melanomas é mau devido a sua alta malígnidade e as rápidas metástases que ocorrem primariamente por via linfática e posteriormente por via hemática, atingindo os mais variados órgãos a distância. Sua malígnidade não se relaciona com a sua pigmentação $\mathrm{e}$ sim com a localização, sendo mais potencialmente malígno quanto maior for a dificuldade de se detectar a drenagem linfática. Metástases regionais estão presentes em 50\% dos casos e são elas responsáveis na maio ria pela morte do paciente. A média de sobrevida dos pacientes tratados 
é pequena e só em alguns raros casos ultrapassam a 5 anos. Trata-se de um tumor de etiologia ainda desconhecida, se bem que, admite-se que a hereditariedade, irradiação, luz solar, inflamações desempenham papel precipitante no aparecimento dos melanomas.

\section{$\begin{array}{llllllll}\mathbf{S} & \mathbf{Y} & \mathbf{N} & \mathbf{O} & \mathbf{P} & \mathbf{S} & \mathbf{I} & \mathbf{S}\end{array}$} A case of primary malignant mela- be done preferently. noma on the upper alveolar ridge is reported in a thirsty six year old white woman. A partiar prohthetic denture acted frobably as an irritative agent producing prechange of color of alveolar mucosa. Radiumtherapy was done as a palliative treatment. The death due to general metastasis occurred in les e than one year. The surgical treatment should

\section{REFERENCIAS BIBLIOGRÁFICAS}

1. AMATO, G. et alii - Melanoma: diagnóstico. Rev. Bras. Cir., Bol. Oncol, 43(4) :299, abr. 1962.

2. BECKER, Jr., S.W. - Pigmentary lesions common to the skin and oral cavity. Oral Surg., 28(4):526, Oct. 1969.

3. CHARKOUDIAN, G.K. - Primary malignant melanoma of the oral cavity. Oral Surg., 28(4):464, Oct 1969.

4. CHAUDHRY, A.P. et alii - Primary malignant melanoma of the oral cavity: a review of 105 cases. Cancer, 11:923, 1958.

5. EPSTEIN, E. et alii - Biopsy adn prognosis of malignant melanoma. JAMA, 20 (8) :1369, May 1969.

6. Opus cit, $p$.

7. GREENE, G. W. et alii - Primary malignant melanoma of the oral mucosa. Oral Surg., 6:1435, 1953.

8. RABELO, E. \& FRAGA, A. -- Atlas de dermatologia. Rio de Janeiro, Guanabara, 1970, p.204.

9. SELDIN, H.M. et alii -- Malignant melanoma: report of a case. Oral Surg., $11(10): 1110,1958$. 